\title{
Intoxicação experimental por Simarouba versicolor (Simaroubaceae) em ovinos e indução de resistência ao consumo da planta ${ }^{1}$
}

\author{
Ariany C. Santos 2 , Tatiane C. Faccin ${ }^{2}$, Nilton M. Carvalho², Paula V. Leal ${ }^{3}$, Arnildo Pott ${ }^{4}$ \\ e Ricardo A. A. Lemos ${ }^{5 *}$
}

\begin{abstract}
Santos A.C., Faccin T.C., Carvalho N.M., Leal P.V., Pott A. \& Lemos R.A.A. 2013. [Experimental poisoning by Simarouba versicolor (Simaroubaceae) in sheep and induced resistance to consumption of the plant.] Intoxicação experimental por Simarouba versicolor (Simaroubaceae) em ovinos e indução de resistência ao consumo da planta. Pesquisa Veterinária Brasileira 33(3):299-304. Faculdade de Medicina Veterinária e Zootecnia, Universidade Federal de Mato Grosso do Sul, Av. Senador Filinto Müller 2443, Campo Grande, MS 79074-460, Brazil. E-mail: ricardo.lemos@ufms.br

Simarouba versicolor St. Hil. is a semideciduous tree belonging to the Simaroubaceae family. An outbreak of poisoning in cattle by shoots of $S$. versicolor present in the pasture in Mato Grosso do Sul and experimental reproduction of the poisoning was described. This study aimed to verify experimentally whether sheep could be used as a clinical-pathological model in the study of the poisoning caused by S. versicolor, to determine if there develops resistance induced by ingestion of small and repeated doses of the leaves, and if the plant keeps its toxicity when dried. Two experiments were conducted: Experiment 1 with green leaves or dried and powdered leave of $S$. versicolor, given in single doses of $5 \mathrm{~g} / \mathrm{kg}, 5 \mathrm{~g} / \mathrm{kg}$ and $3 \mathrm{~g} / \mathrm{kg}$ to three sheep (Sheep 1, 2 and 3 respectively). Experiment 2 was made with different daily doses of dried and powdered leaves of $S$. versicolor; to four sheep was given $1.5 \mathrm{~g} /$ $\mathrm{kg}, 0.75 \mathrm{~g} / \mathrm{kg}, 0.6 \mathrm{~g} / \mathrm{kg}$ and $0.3 \mathrm{~g} / \mathrm{kg}$, and the positive control (Sheep 4 ) received $3 \mathrm{~g} / \mathrm{kg}$. The administration was suspended when the animals showed clinical signs of poisoning. After twelve days of recovery, the surviving sheep were challenged with the same daily dose given previously, to assess the development of resistance. Clinical signs observed in both experiments were characterized by anorexia, congested ocular mucosa, polydipsia, drooling, loose stools which evolved into fetid greenish watery diarrhea, lateral decumbency and death of Sheep 1 to 7. The main histological lesions observed were necrosis of lymphoid tissue (lymph nodes, spleen, Peyer's patches) and necrotizing enteritis. With the results it can be concluded that sheep can be used as experimental model for the clinic-pathological aspects of poisoning by $S$. versicolor. The method used has not shown resistance to the daily consumption of the plant by the sheep, and the leaves kept their toxicity when dried.
\end{abstract}

INDEX TERMS.- Poisonous plants, Simarouba versicolor, Simaroubaceae, lymphoid necrosis, necrotizing enteritis, plant poisoning, sheep.

\footnotetext{
${ }^{1}$ Recebido em 10 de outubro de 2012.

Aceito para publicação em 5 de dezembro de 2012.

${ }^{2}$ Programa de Pós-Graduação em Ciência Animal, Faculdade de Medicina Veterinária e Zootecnia (FAMEZ), Universidade Federal de Mato Grosso do Sul (UFMS), Av. Senador Filinto Müller 2443, Campo Grande, MS 79074-460, Brasil.

${ }^{3}$ Bolsista de Iniciação Científica PIBIC-CNPq, FAMEZ/UFMS, Campo Grande, MS.

${ }^{4}$ Laboratório de Botânica, Centro de Ciências Biológicas e da Saúde (CCBS), UFMS, Cidade Universitária s/n, Campo Grande, MS 79070-900.

${ }^{5}$ FAMEZ /UFMS, Campo Grande, MS. *Autor para correspondência: ricardo.lemos@ufms.br
}

RESUMO.- Simarouba versicolor é uma árvore semidecídua pertencente à família Simaroubaceae. Um surto de intoxicação por $S$. versicolor em bovinos por brotos da planta presente no pasto em Mato Grosso do Sul e sua reprodução experimental foram descritos. Esse estudo teve por objetivos verificar experimentalmente se os ovinos podem ser utilizados como modelo clínico-patológico no estudo da intoxicação por Simarouba versicolor St. Hil. (fam. Simaroubaceae), determinar se há indução de resistência pela ingestão de pequenas e repetidas doses e, se a planta mantém sua toxicidade quando dessecada. Foram realizados 
dois experimentos, sendo o primeiro com folhas verdes ou folhas dessecadas e trituradas de S. versicolor em doses únicas de $5 \mathrm{~g} / \mathrm{kg}, 5 \mathrm{~g} / \mathrm{kg}$ e $3 \mathrm{~g} / \mathrm{kg}$ a três ovinos (Ovino 1,2 e 3 respectivamente). 0 experimento 2 , foi realizado com diferentes doses diárias de folhas dessecadas e trituradas de $S$. versicolor em quatro ovinos que receberam $1,5 \mathrm{~g} / \mathrm{kg}$, $0,75 \mathrm{~g} / \mathrm{kg}, 0,6 \mathrm{~g} / \mathrm{kg}$ e $0,3 \mathrm{~g} / \mathrm{kg}$ e, com um ovino que recebeu $3 \mathrm{~g} / \mathrm{kg}$ como controle positivo (Ovino 4). A administração foi suspensa quando os ovinos apresentaram sinais clínicos da intoxicação. Após doze dias de recuperação, os animais sobreviventes foram desafiados com a mesma dose diária da planta ingerida anteriormente para avaliar o desenvolvimento de resistência. Os sinais clínicos observados nos dois experimentos caracterizaram-se por anorexia, mucosas oculares congestas, polidipsia, sialorreia, fezes pastosas que evoluíram para diarreia líquida fétida esverdeada, decúbito lateral e morte para os Ovinos 1 a 7 . As principais lesões histológicas observadas foram necrose do tecido linfoide (linfonodos, baço, placas de Peyer) e enterite necrosante. Com os resultados obtidos, pode-se concluir que os ovinos podem ser utilizados como modelo experimental clínico-patológico na intoxicação por $S$. versicolor. Com o método utilizado, não houve resistência ao consumo diário de folhas da planta pelos ovinos e, as folhas mantiveram sua toxicidade quando dessecadas.

TERMOS DE INDEXAÇÃO.- Plantas tóxicas, Simarouba versicolor, Simaroubaceae, necrose linfoide, enterite necrosante, intoxicação por plantas, ovinos.

\section{INTRODUÇÃO}

Simarouba versicolor, conhecida popularmente como perdiz, pé-de-perdiz ou pau-paraíba, é uma árvore semidecídua pertencente à família Simaroubaceae (Mesquita 1997). No Brasil, é encontrada desde o Nordeste até o Estado de São Paulo e em alguns pontos dos Estados do Pará e Mato Grosso do Sul (Lorenzi 1998). No Pantanal, por ser raramente pastejada, os produtores da região acreditam que a planta seja tóxica (Pott \& Pott 1994).

Apesar de sua ampla distribuição, até o momento apenas um surto de intoxicação por $S$. versicolor em bovinos foi descrito no município de Água Clara, Mato Grosso do Sul, no qual as principais lesões foram caracterizadas por necrose do tecido linfoide (linfonodos, baço, placas de Peyer) e enterite necrosante. Os exemplares da planta encontravam-se com cerca de um metro de altura e pastejados pelos bovinos. A intoxicação foi reproduzida experimentalmente em bovinos com lesões semelhantes às observadas no surto $\mathrm{e}$ nesta espécie a planta não demonstrou efeito acumulativo (Carvalho et al. 2012).

Até o momento, não há relatos da intoxicação espontânea ou experimental em ovinos por $S$. versicolor e, um modelo experimental para avaliar o desenvolvimento da resistência ao consumo da planta, definida como ao aumento progressivo da capacidade do organismo em eliminar a substância tóxica sem causar danos (Tokarnia et al. 2012).

Este trabalho tem como objetivos verificar se os ovinos podem ser utilizados como modelo experimental da intoxicação por $S$. versicolor, determinar se há indução de resis- tência pela ingestão de pequenas e repetidas doses e, se a planta mantém sua toxicidade quando dessecada.

\section{MATERIAL E MÉTODOS}

Amostras de folhas de Simarouba versicolor St.Hil. (fam. Simaroubaceae) (Fig.1) foram colhidas em uma propriedade no município de Água Clara em Mato Grosso do Sul, Brasil, onde ocorreram casos de intoxicação pela planta em bovinos (Carvalho et al. 2012). Os exemplares da planta encontravam-se em fase de brotação, com cerca de um metro de altura, e pastejados pelos bovinos. Foram utilizadas folhas verdes, conservadas em sacos plásticos a $-5^{\circ} \mathrm{C}$, e folhas dessecadas à sombra. Para a estimativa do peso da planta seca correspondente ao peso da planta fresca foram separadas 1000 gramas de folhas verdes para dessecação, obtendo-se a diferença entre folhas verdes/dessecadas de 58,87\%.

Foram realizados dois experimentos, conforme delineamento no Quadro 1, sendo a administração da planta por via oral forçada. No início dos experimentos, os ovinos foram previamente pesados, mantidos em baias individuais, com água, feno de alfafa e ração. Os ovinos foram submetidos ao exame clínico antes da administração da planta e diariamente durante toda a experimentação.

O Experimento 1 foi realizado com três ovinos, machos, de seis meses de idade, sem raça definida e identificados como Ovinos 1 a 3. Ovino 1 recebeu uma dose de $5 \mathrm{~g} / \mathrm{kg}$ de folhas verdes inteiras e os Ovinos 2 e 3 receberam doses únicas de $5 \mathrm{~g} / \mathrm{kg}$ e $3 \mathrm{~g} / \mathrm{kg}$ de folhas dessecadas trituradas, respectivamente, para verificar se a espécie pode ser utilizada como modelo experimental do quadro-clínico patológico no estudo da intoxicação por $S$. versicolor em bovinos e, se a planta mantém sua toxicidade quando dessecada.

Para estabelecer um modelo experimental de indução de re-
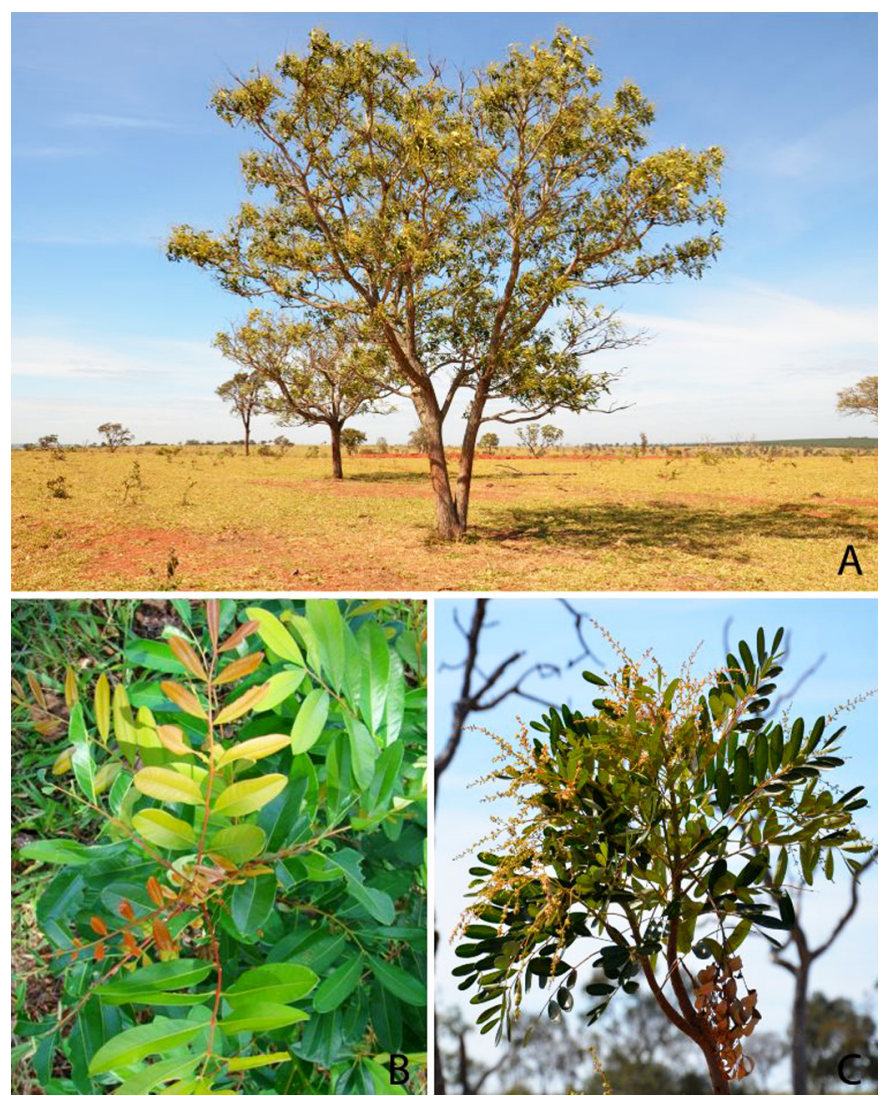

Fig.1. Simarouba versicolor: (A) a árvore, (B) as folhas, (C) a inflorescência. 


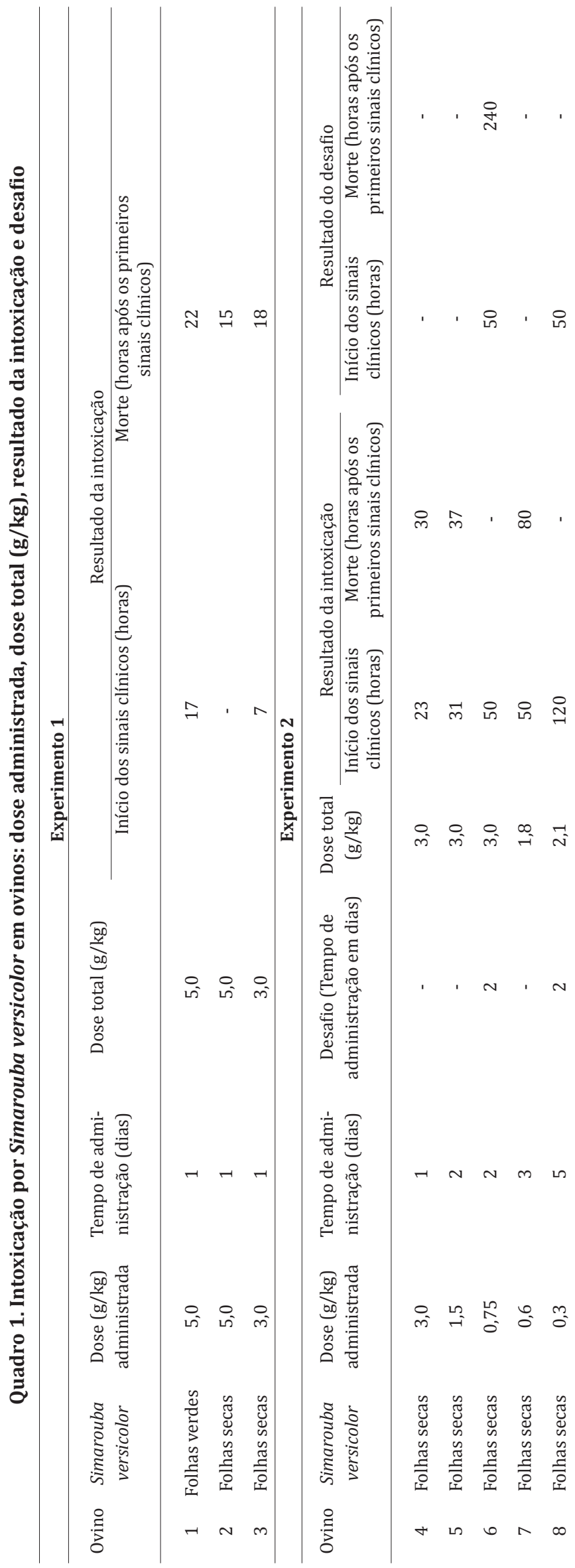

sistência ao consumo diário da planta, o Experimento 2 foi realizado com folhas dessecadas administradas a cinco ovinos, machos, de seis meses de idade, sem raça definida e identificados de 4 a 8 . Ovino 4 foi utilizado como controle positivo recebendo dose única de $3 \mathrm{~g} / \mathrm{kg}$, os ovinos de 5 a 8 receberam doses diárias não letais de $1,5 \mathrm{~g} / \mathrm{kg}, 0,75 \mathrm{~g} / \mathrm{kg}, 0,6 \mathrm{~g} / \mathrm{kg}$ e $0,3 \mathrm{~g} / \mathrm{kg}$ respectivamente, das folhas dessecadas (Quadro 1), calculadas com base nas doses utilizadas no experimento 1. A administração foi suspensa quando os ovinos apresentaram sinais clínicos da intoxicação, semelhantes aos descritos por Carvalho et al. (2012) em bovinos. Após a recuperação clínica, que ocorreu com 12 dias após a última administração da planta, os animais sobreviventes foram desafiados com a mesma dose diária anteriormente ingerida.

Os experimentos foram aprovados pela Comissão de Ética no Uso de Animais (CEUA) da UFMS e protocolados sob nํㅜ 400/2012.

\section{RESULTADOS}

\section{Achados clínicos}

Nos ovinos do Experimento 1 (Ovinos 1 a 3), os sinais clínicos foram semelhantes e caracterizaram-se por apatia, anorexia, mucosas oculares congestas, polidipsia, bruxismo, fezes pastosas que evoluíram para diarreia líquida fétida esverdeada, decúbito lateral e morte. A evolução clínica em horas, do início dos sinais clínicos até a morte variou de 15 a 22 horas (Quadro 1). No Ovino 2, não foi possível observar o início dos sinais clínicos, pois o animal foi encontrado morto 15 horas após a administração da planta.

Ovino 4 (controle positivo) e Ovino 5 do Experimento 2 , desenvolveram sinais clínicos similares aos observados nos ovinos do Experimento 1, exceto diarreia. Após a ingestão total de 1,8g/kg das folhas de Simarouba versicolor em três administrações, o ovino 7 apresentou apatia, anorexia, fezes pastosas a diarreia líquida fétida esverdeada a sanguinolenta, decúbito lateral e respiração abdominal, sendo eutanasiado in extremis.

Ovinos 6 e 8, que apresentaram sinais clínicos da intoxicação com dois e cinco dias, respectivamente, recuperaram-se após a suspensão da administração da planta. Doze dias após a recuperação, os animais receberam $0,75 \mathrm{~g} / \mathrm{kg} \mathrm{e} 0,3 \mathrm{~g} /$ $\mathrm{kg}$ de $S$. versicolor, respectivamente, desenvolvendo apatia, anorexia, fezes pastosas que evoluíram para diarreia líquida fétida esverdeada e queda total de lã, com a ingestão de apenas duas doses. 0 ovino 8 apresentou melhora do quadro clínico quatro dias depois de cessada a administração da planta e o ovino 6 morreu 10 dias após a última dose administrada.

\section{Achados de necropsia}

Todos os ovinos necropsiados (Ovinos 1 a 7) apresentaram lesões semelhantes no abomaso, intestinos e linfonodos, porém em diferentes intensidades. Na mucosa do abomaso havia extensas áreas avermelhadas e edematosas, sendo mais acentuadas nos Ovinos 2, 3 e 5. Nos intestinos delgado e grosso, a mucosa e serosa apresentavam-se difusamente avermelhadas e edematosas, com maior intensidade nos Ovinos 1, 2, 5 e 7. Apenas o ovino 6 apresentou conteúdo intestinal sanguinolento.

Os linfonodos estavam aumentados de tamanho, com a superfície de corte avermelhada, acentuadamente hemorrágicos e edematosos nos Ovinos 2, 3 e 5 . No ovino 1 , 
observaram-se hemorragias no pericárdio e nos Ovinos 2, 3 e 5 havia hemorragias multifocais no endocárdio.

\section{Achados histológicos}

Os achados histológicos foram semelhantes nos Ovinos 1 a 7 (Quadro 2), mas com intensidades diferentes, caracterizando-se por necrose do tecido linfoide e enterite necrosante. As alterações histológicas incluíram depleção e necrose do tecido linfoide à ausência de centros germinativos em linfonodos (Fig.2), baço e placas de Peyer (Fig.3). Nos Ovinos 1 e 3 observou-se necrose fibrinoide moderada difusa da parede dos vasos dos linfonodos e eritrofagocitose nos linfonodos dos Ovinos 1, 4, 6 e 7. Também foram observadas necrose discreta a moderada do tecido linfoide peribronquial nos Ovinos 3 e 4.

Necrose difusa da superfície do epitélio do abomaso que se estendia as criptas e submucosa foram mais acentuadas nos Ovinos 5 e 7, com discreta a moderada hemorragia. Enterite necrosante foi um achado comum em todos os ovinos do experimento, variando de intensidade moderada a acentuada, e com intensa necrose das placas de Peyer nos Ovinos 4 e 5 .

Nos Ovinos 6 e 7 observaram-se ainda acentuada tumefação e vacuolização do citoplasma dos hepatócitos, associada a áreas focalmente extensivas de necrose. Outras alterações histológicas, como discretos e múltiplos focos de degeneração e necrose da mucosa, associada a detritos celulares e neutrófilos degenerados, foram observadas nos

Quadro 2. Principais alterações histológicas e intensidade de acordo com a localização na intoxicação experimental por Simarouba versicolor em ovinos

\begin{tabular}{|c|c|c|c|c|c|c|c|c|}
\hline \multirow{2}{*}{$\begin{array}{l}\text { Órgão } \\
\text { afetado }\end{array}$} & \multirow[t]{2}{*}{ Alterações histológicas } & \multicolumn{7}{|c|}{ Ovino $\mathrm{n}^{\mathrm{o}}$} \\
\hline & & 1 & 2 & 3 & 4 & 5 & 6 & 7 \\
\hline \multirow[t]{6}{*}{ Linfonodos } & Rarefação do tecido linfoide & $+*$ & +++ & ++ & ++ & ++ & +++ & ++ \\
\hline & $\begin{array}{l}\text { Rarefação de centro germi- } \\
\text { nativo }\end{array}$ & + & +++ & +++ & ++ & ++ & +++ & + \\
\hline & Necrose do tecido linfoide & + & +++ & ++ & +++ & ++ & + & ++ \\
\hline & $\begin{array}{l}\text { Necrose fibrinoide da parede } \\
\text { de vasos }\end{array}$ & ++ & - & ++ & - & - & - & - \\
\hline & Hemorragia e edema & + & ++ & + & + & + & - & + \\
\hline & $\begin{array}{l}\text { Macrófagos com eritrofago- } \\
\text { citose }\end{array}$ & ++ & - & - & ++ & - & ++ & +++ \\
\hline \multirow[t]{3}{*}{ Baço } & Rarefação do tecido linfoide & + & - & + & - & + & - & ++ \\
\hline & Necrose do tecido linfoide & ++ & + & ++ & ++ & + & - & + \\
\hline & Congestão e hemorragia & ++ & +++ & +++ & + & ++ & + & +++ \\
\hline \multirow[t]{4}{*}{ Abomaso } & Necrose da camada mucosa & - & + & + & + & ++ & + & +++ \\
\hline & Congestão e hemorragia & + & + & + & + & + & + & ++ \\
\hline & $\begin{array}{l}\text { Infiltrado inflamatório/detri- } \\
\text { tos celulares na mucosa }\end{array}$ & + & - & - & - & - & + & - \\
\hline & $\begin{array}{l}\text { Infiltrado inflamatório/detri- } \\
\text { tos celulares na submucosa }\end{array}$ & +++ & - & - & - & - & - & + \\
\hline \multirow{5}{*}{ Intestinos } & Necrose da camada mucosa & ++ & +++ & +++ & +++ & +++ & ++ & +++ \\
\hline & Necrose das placas de Peyer & + & + & ++ & +++ & +++ & - & ++ \\
\hline & Congestão e hemorragia & + & + & ++ & ++ & + & + & ++ \\
\hline & $\begin{array}{l}\text { Infiltrado inflamatório mono- } \\
\text { nuclear na mucosa }\end{array}$ & ++ & ++ & +++ & - & + & - & - \\
\hline & $\begin{array}{l}\text { Infiltrado inflamatório/detri- } \\
\text { tos celulares na submucosa }\end{array}$ & - & - & - & - & - & - & ++ \\
\hline \multirow[t]{2}{*}{ Fígado } & $\begin{array}{l}\text { Tumefação e vacuolização de } \\
\text { hepatócitos }\end{array}$ & + & + & + & + & - & & +++ \\
\hline & $\begin{array}{l}\text { Áreas de necrose de hepató- } \\
\text { citos }\end{array}$ & - & ++ & + & + & + & +++ & ++ \\
\hline
\end{tabular}

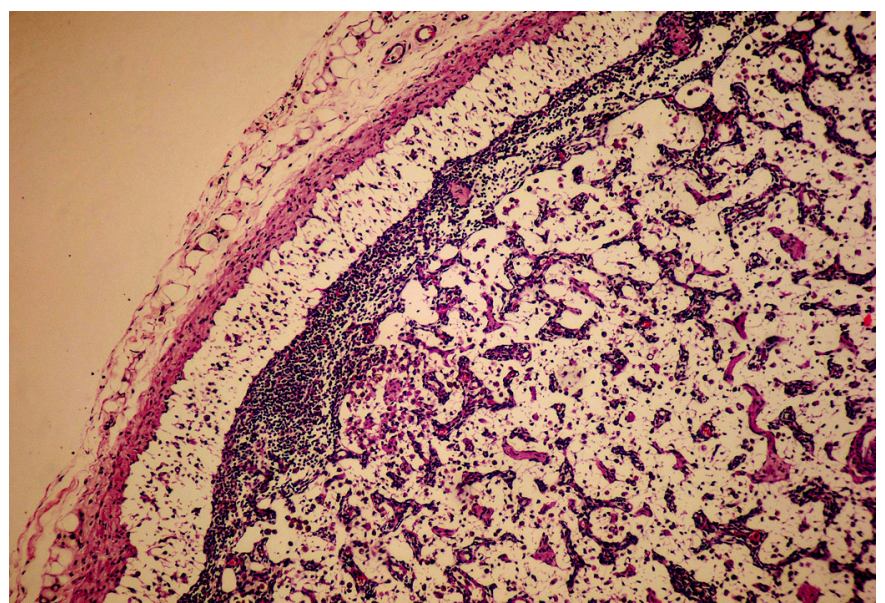

Fig.2. Linfonodo com acentuada depleção e necrose de células linfoides e ausência de centros germinativos com perda da arquitetura do órgão, na intoxicação experimental por Simarouba versicolor em ovinos (Ovino 7). HE, obj.10x.

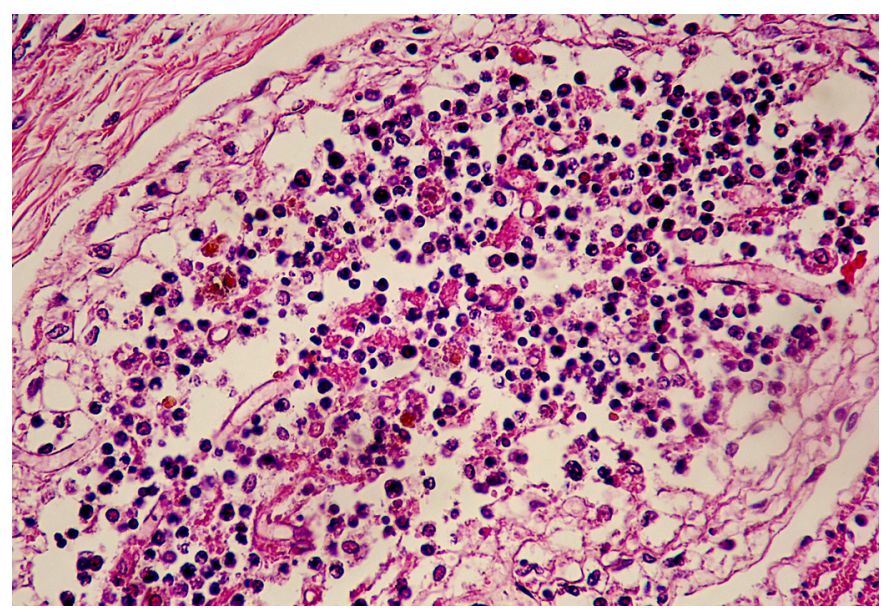

Fig.3. Placa de Peyer com acentuada depleção e necrose do folículo linfoides, na intoxicação experimental por Simarouba versicolor em ovinos (Ovino 4). HE, obj.40x.

pré-estômagos dos Ovinos 2, 4, 5, 6 e 7. Evidenciou-se hemorragia focalmente extensiva acentuada no endocárdio, que se estendia ao miocárdio no Ovino 2.

\section{DISCUSSÃO}

O quadro clínico, achados de necropsia e alterações histológicas observados na intoxicação experimental por Simarouba versicolor em ovinos foram semelhantes aos descritos na intoxicação espontânea e experimental em bovinos (Carvalho et al. 2012), indicando que os ovinos podem ser utilizados como modelo experimental para estudo do quadro clínico-patológico na intoxicação pela planta. Outro dado relevante refere-se a toxicidade da planta, que mesmo dessecada causou intoxicação nos ovinos.

No Experimento 2, os Ovinos 6 e 8 desenvolveram sinais clínicos logo após receberem as doses desafio, doze dias após recuperação clínica, totalizando $3 \mathrm{~g} / \mathrm{kg}$ e $2,1 \mathrm{~g} / \mathrm{kg}$, respectivamente. Caso semelhante ocorreu com os Ovinos 5 e 7, que apresentaram sinais clínicos e morreram com duas e três doses da planta, recebendo ao final $3, \mathrm{~g} / \mathrm{kg}$ e $1,8 \mathrm{~g} /$ 
$\mathrm{kg}$, respectivamente. Esses resultados sugerem a possibilidade de $S$. versicolor possuir efeito acumulativo em ovinos, o qual não foi observado na intoxicação experimental em bovinos (Carvalho et al. 2012).

Com as doses e métodos utilizados, não foi observada a indução de resistência ao consumo diário de S. versicolor. Anjos et al. (2010), em experimentos com delineamento semelhante, com sementes de Crotalaria retusa em ovinos, demonstraram que com a ingestão diária de doses não letais há indução de resistência ao princípio tóxico (monocrotalina) da planta, provavelmente associada à capacidade das enzimas hepáticas para desintoxicar alcaloides pirrolizidínicos ou pela aquisição de resistência pela rápida adaptação da microbiota ruminal em metabolizar a monocrotalina.

A queda total de lã observada nos Ovinos 6 e 8 do Experimento 2 foi semelhante ao efeito depilatório descrito na intoxicação por Leucaena leucocephala em ovinos (Almeida et al. 2006). A queda de pelos na intoxicação aguda por esta planta se deve a ação da mimosina, incompletamente degradada no rúmen (Tokarnia et al. 2012). Considerando que os animais do presente estudo apresentaram quadro clínico severo afetando outros sistemas, é provável que a queda de lã seja secundária as lesões em outros tecidos e não um efeito primário como ocorre na intoxicação por $L$. leucocephala. Entretanto, estudos complementares com doses não letais de S. versicolor poderão indicar se a planta possui um princípio tóxico capaz de causar o efeito depilatório.

As lesões histológicas no tecido linfoide observadas nos ovinos intoxicados experimentalmente por $S$. versicolor, são muito semelhantes às descritas em intoxicações em ruminantes por outras plantas como Riedeliella graciliflora (Nobre et al. 1989, Riet-Correa et al. 2001), Polygala klotzschii (Camargo et al. 1968, Tokarnia et al. 1976), Baccharis coridifolia (Rozza et al. 2006) e Baccharis megapotamica (Armién et al. 1993, Driemeier et al. 2000). Tricotecenos macrocíclicos foram identificados em $B$. coridifolia e $B$. megapotamica (Kupchan et al. 1977, Busam 1985), e em P. klotzschii foi isolada a 5-metoxi-podofilotoxina (Busam 1985), estas substâncias são consideradas como princípios tóxicos destas plantas. Em estudos realizados com caules de $S$. versicolor foram isoladas cumarinas (Simote 2006). Embora as cumarinas sejam capazes de provocar quadros hemorrágicos em diferentes espécies (McGavin \& Zachary 2009) e em alguns trabalhos serem descritas por possuírem efeito citostático (Kasinadhuni et al. 1999) e imunossupressor (Houl \& Payá 1996), nas intoxicações espontâneas e experimentais não há relatos de lesões gastrointestinais e em tecido linfoide. Isto sugere que Simarouba versicolor pode ter mais de um princípio tóxico ou que há um princípio responsável pelas lesões ainda não isolado.

Em outros estudos com folhas de S. versicolor, já foram isoladas substâncias como quassinoides (Ghosh et al. 1977), triterpenoides e flavonoides (Simote 2006), entretanto, não há modelos experimentais que descrevam estas substâncias como responsáveis pelas lesões observadas na intoxicação de ruminantes. Este fato ressalta a importância de estudos para elucidação da patogenia utilizando substâncias isoladas das folhas de $S$. versicolor, usando o ovino como modelo experimental. A escolha desta espécie para experimentação é atribuída ao menor custo na aquisição dos animais e por serem mais dóceis no manejo que bovinos (Stigger et al. 2001), além de ser uma espécie sensível a planta e por apresentar quadro clínico-patológico da intoxicação semelhante ao bovino.

\section{CONCLUSÕES}

Com os resultados obtidos, pode-se concluir que:

- Ovinos podem ser utilizados como modelo experimental para estudo do quadro clínico-patológico na intoxicação por Simarouba versicolor, apresentando necrose do tecido linfoide (linfonodos, baço, placas de Peyer) e enterite necrosante semelhante ao observado em bovinos;

- As folhas da árvore mantiveram sua toxicidade quando dessecadas; e,

- Com o método utilizado, não foi observada resistência ao consumo diário de folhas da planta pelos ovinos.

Agradecimentos.- À Fundação de Apoio ao Desenvolvimento do Ensino, Ciência e Tecnologia do Estado de Mato Grosso do Sul (Fundect, Proc. no 14/2009-Universal) pelo apoio financeiro e ao Conselho Nacional de Desenvolvimento Científico e Tecnológico (CNPq no 14/2011 - Projeto Universal Proc.483211/2012-5). À Coordenação de Aperfeiçoamento de Pessoal de Nível Superior (CAPES) pela concessão de bolsa de mestrado.

\section{REFERÊNCIAS}

Almeida A.P.M.G., Kommers G.D., Nogueira A.P.A., Júnior L.G.B., Prado Marques B.M.F. \& Lemos R.A.A. 2006. Avaliação do efeito tóxico de Leucaena leucocephala (Leg. Mimosoideae) em ovinos. Pesq. Vet. Bras. 26:190194.

Armién A.G., Peixoto P.V. \& Tokarnia C.H. 1993. Intoxicação experimental por Baccharis megapotamica var. megapotamica e var. weirii (Compositae) em ovinos. Pesq. Vet. Bras. 13:5-20.

Anjos B.L., Nobre V.M.T., Dantas A.F.M., Medeiros R.M.T., Oliveira Neto T.S., Molyneux R.J. \& Riet-Correa F. 2010. Poisoning of sheep by seeds of Crotalaria retusa: Acquired resistance by continuous administration of low doses. Toxicon 55:28-32.

Busam L. 1985. Über die Gifte aus Baccharis coridifolia und Polygala klotzschii. Dissertation, Hannover, 275 S.

Camargo W.V.A., Mengato W., Platzech F. \& Morita T. 1968. Intoxicação de bovinos pela Polygala klotzschii Chodat, na região do Pontal (estado de São Paulo). Biológico 34:221-223.

Carvalho N.M., Santos A.C., Faccin T.C., Bacha F.B., Carvalho A.Q., Pott A. \& Lemos R.A.A. 2012. Intoxicação espontânea e experimental por Simarouba versicolor (Simaroubaceae) em bovinos. VII Endivet, Porto Alegre, RS. (Resumo)

Driemeier D., Cruz C. \& Loretti A. 2000. Baccharis megapotamica var. weirii poisoning in Brazilian cattle. Vet. Human. Toxicol. 42:220-221.

Ghosh P.C., Larrahondo J.E., Le Quesne P.W. \& Raffauf R.F. 1977. Antitumor Plants. IV. Constituents of Simarouba versicolor. J. Nat. Prod. 40:364-369.

Hoult J.R.S. \& Payá M. 1996. Pharmacological and biochemical actions of simple coumarins: natural products with therapeutic potential. Gen. Pharmacol. 27:713-722.

Kasinadhuni V.R.R., Rajashekhar G., Rajgopalan R., Sharma V.M., Vamsi Krishna C., Sairam P., Sai Prasad G., Sadhukhan S. \& Gangadhar Rao G. 1999. Anti-ulcer potential of Halinta coridifolia. Fitoterapia 70:93-95.

Kupchan S.M., Streelman D.R., Jarvis B.B., Dailey R.G. \& Sneden A.T. 1977. Isolation of potent new antileukemic trichothecenes from Baccharis megapotamica. J. Org. Chem. 42:4221-4225. 
Lorenzi H. 1998. Árvores brasileiras: manual de identificação e cultivo de plantas arbóreas do Brasil. Vol.2. Instituto Plantarum de Estudos da Flora, Nova Odessa, SP. 324p.

McGavin M.D. \& Zachary J.F. 2009. Bases da Patologia em Veterinária. 4a ed. Elsevier, Rio de Janeiro. 877p.

Mesquita A.G. 1997. Contribuição ao conhecimento químico de plantas do Nordeste do Brasil: Simarouba versicolor (Simaroubaceae). Dissertação de Mestrado em Química Orgânica, Universidade Federal do Ceará, Fortaleza. 119p.

Nobre D., Cappellaro C.E.M.P.D.M. \& Souza A.C. 1989. Riedeliella graciliflora: estudo toxicológico em cobaias e ruminantes. Arqs Inst. Biológico, São Paulo, 56:39-42.

Pott A. \& Pott V.J. 1994. Plantas do Pantanal. Embrapa Pantanal, Corumbá, MS. 320p.

Riet-Correa F., Górniak S.L., Haraguchi M. \& Dagli M.L.Z. 2001. Histological changes caused by experimental Riedeliella graciliflora (Leg. Papilionoideae) poisoning in cattle and laboratory animals. Pesq. Vet. Bras. 21:5-7.
Rozza D.B., Paymundo D.L., Corrêa A.M.R., Leal J., Seitz A.I., Driemeier D. \& Colodel E.M. 2006. Intoxicação espontânea por Baccharis coridifolia (Compositae) em ovinos. Pesq. Vet. Bras. 26:21-25.

Simote S.Y. 2006. Estudo fitoquímico de Helietta puberula (Rutaceae), Simarouba versicolor (Simaroubaceae) e busca de um processo de microencapsulação de compostos ativos, visando o controle de formigas cortadeiras. Tese de Doutorado em Química, Universidade Federal de São Carlos, São Carlos, SP. 200p.

Stigger A.L., Barros C.S.L., Langohr I.M. \& Barros S.S. 2001. Intoxicação experimental por Ateleia glazioviana (Leg. Papilionoideae) em ovinos. Pesq. Vet. Bras. 21:98-108.

Tokarnia C.H., Döbereiner J. \& Canella C.F.C. 1976. Intoxicação experimental por Polygala klotzschii em bovinos. Pesq. Agropec. Bras. 11:7386.

Tokarnia C.H., Brito M.F., Barbosa J.D., Peixoto P.V. \& Döbereiner J. 2012. Plantas Tóxicas do Brasil. 2 ${ }^{\underline{a}}$ ed. Helianthus, Rio de Janeiro. 586p. 